\title{
ANALISIS PERAN SUPERVISI KEPALA SEKOLAH TERHADAP PELAKSANAAN TUGAS POKOK GURU DI SMK NEGERI 1 KERINCI TAHUN PELAJARAN 2018/2019
}

\author{
ALMI ZUKRI \\ Kepala SMK Negeri 1 Kerinci Provinsi Jambi \\ Email : almizukri74@gmail.com
}

\begin{abstract}
ABSTRAK
Penelitian Tindakan Sekolah (PTS) ini dilaksanakan pada semester pertama tahun pelajaran 2018/2019. Hal ini diputuskan setelah mengamati pelaksanaan tugas pokok guru dalam menyusun perencanaan, melaksanaan proses pembelajaran dan dalam mengevaluasi proses pembelajaran dinilai belum maksimal. Pelaksanaan tugas guru dalam merencanakan pembelajaran akan dilihat dari Rencana Pelaksanaan Pembelajaran (RPP) dan batas pembelajaran yang disusun guru. Berdasarkan hasil pengamatan pada penelitian tindakan siklus pertama dan kedua, ternyata supervisi yang dilaksanakan kepala sekolah dapat meningkatkan pelaksanaan tugas pokok guru. Hal ini membuktikan bahwa supervisi kepala sekolah punya peranan yang sangat penting dalam meningkatkan pelaksanaan tugas pokok guru.
\end{abstract}

Kata Kunci : supervisi kepala sekolah, tugas pokok guru

\section{PENDAHULUAN}

Era reformasi pendidikan sangatlah monumental dalam sejarah pendidikan di Negara Republik Indonesia ini, dimana otoritas yang sangat besar diberikan langsung pada sekolah. Sekolah bisa mengembangkan inovasinya masing-masing dalam mengembangkan perlakuan pada siswa dalam belajar, bahkan sekolah diberi kewenangan untuk menetapkan kebijakan sendiri. Sejalan dengan tantangan kehidupan global, pendidikan merupakan hal yang sangat penting karena pendidikan salah satu penentu mutu sumber daya manusia. Dewasa ini keunggulan suatu bangsa bukan lagi diidentikkan dengan melimpahnya ruangnya kekayaan alam yang ada, akan tetapi lebih kepada keunggulan sumber daya manusianya, karena mutu sumber daya manusia berkontribusi positif bagi mutu pendidikan. Mutu pendidikan sering dinilai dengan kondisi yang baik, syarat yang terpenuhi, serta komponen yang komplit dalam pendidikan. Komponen-komponen tersebut adalah masukan, proses, keluaran, tenaga kependidikan, sarana dan prasarana, serta biaya.

Kepala sekolah adalah pemegang kunci keberhasilan keberlangsungan pendidikan di sekolah yang dipimpinnya. Kepala Sekolah memiliki peranan yang dominan untuk mendorong upaya inovasi baik yang berasal dari luar maupun yang timbul dari dalam sekolahnya. (Ekosiswoyo, 2016). Demikian juga kepala sekolah mendapat tuntutan peran yangsangat besar. Kepala sekolah harus memiliki gaya kepemimpinan yang kuat untuk mendorong seluruh pendidiknya bekerja total dalam mendidik siswa-siswinya, memiliki visi untuk kemajuan sekolah, konsisten dengan visinya, tapi tetap demokratis dan menghargai pandangan parastaf (Fitrah, 2017). Agar hal demikian tercapai dengan baik, maka kepemimpinan kepala sekolah perlu diberdayakan, sehingga kepala sekolah mampu berperan sesuai dengan tugas, wewenang, dan tanggung jawabnya (Purwanti, Murniati danYusrizal, 2014). Kepala sekolah juga harus memiliki ekspektasi yang baik pada para siswanya, memberikan penguatan keterampilan dasar untuk siswa-siswinya, sehingga bisa berkembang dengan baik dalam profesi apapun, dan mampu menciptakan suasana yang kondusif untuk para guru dan karyawan serta menciptakan suasana yang nyaman untuk siswa (Rosyada, 2013: 24).

Bertindak sebagai kepala sekolah tidaklah mudah dilakukan oleh sembarang orang dalam menjalankan tugasnya sebagai pemimpin pendidikan. Kepala sekolah mempunyai tanggung jawab yang besar dalam membimbing setiap sumber daya manusia yang ada disekitarnya agar bisa berkembang (Ramadoni, Kusmintardjo, \& Arifin, 2016). Sebagai orang yang punya peranan, kepala sekolah bertanggung jawab membantu, membimbing dan 
mengarahkan guru-guru yang mendapat kesulitan dalam pelaksanaan tugas. Proses kegiatan membantu memecahkan permasalahan yang dihadapi guru tersebut dinamakan supervisi. Supervisi yang dilaksanakan kepala sekolah secara efektif dan berkelanjutan diharapkan akan memberikan kontribusi yang cukup besar terhadap guru-guru dalam usahanya memperbaiki dan meningkatkan cara kerja mereka dari waktu ke waktu (Ariana, Dantes, \& Lasmawan, 2015). Disamping itu pula supervisi yang efektif dan professional akan menimbulkan kepuasan kerja bagi yang dipimpinnya. Istilah kepuasan kerja dalam penelitian ini mengacu pada apa yang dirasakan guru tentang pekerjaan mengajar mereka. Kepuasan kerja guru dapat secara signifikan mempengaruhi aspek kehidupan sekolah berkaitan dengan komitmen kerjanya (Bogler \& Nir, 2015). Maka demikian bahwa kata kunci supervisi adalah memberikan pelayanan dan bantuan kepada guru-guru, maka tujuan supervisi adalah memberikan layanan dan bantuan untuk mengembangkan situasi belajar-mengajar yang dilakukan guru dikelas. Dengan demikian jelas bahwa supervisi ialah memberikan layanan dan bantuan untuk meningkatkan kualitas mengajar guru dikelas yang pada gilirannya untuk meningkatkan kualitas belajar-mengajar siswa (Mette, Range, Anderson, Hvidston, \& Nieuwenhuizen, 2015).

Kepemimpinan dalam lingkungan satuan pendidikan selalu melibatkan upaya seorang kepala sekolah untuk mempengaruhi perilaku organisasi, para pengikut/guru dalam suatu situasi. Agar kepala sekolah dapat melaksanakan fungsi kepemimpinannya, dia bukan saja harus memiliki wibawa tetapi harus memiliki kesanggupan untuk menggunakan wibawa ini terhadap para guru supaya diperoleh kompetensi profesional guru yang baik. (Nirwana \& Murniati, 2015). Strategi kepala sekolah memegang peranan yang sangat penting dalam pengembangan profesional guru sehingga keberhasilan proses belajar mengajar disekolah dapat tercapai dengan baik. Kondisi tersebut akan sangat membantu dalam upaya meningkatkan mutu peserta didik, karena output yang berkualitas salah satunya akan lahir dari proses pembelajaran yang dikelola oleh seorang guru yang memiliki profesionalitas di bidangnya. Guru yang profesional sangat diperlukan adanya pembinaan dan pengembangan yang kontinyu dari petugas, baik oleh guru senior, kepala sekolah maupun pengawas. Dengan memahami dan memenuhi kebutuhan guru dalam meningkatkan kompetensi dan kualitas pengajarannya, maka akan terbangun persepsi yang baik atas manajerial kepala sekolah. Sub indikator dari gaya kepemimpinan yang berorientasi pada kebutuhan bawahan yakni memberikan petunjuk, melaksanakan pengawasan, menanamkan keyakinan, menekankan pentingnya pelaksanaan tugas, memberi motivasi, dan mengembangkan hubungan kekeluargaan. (Park \& Ham, 2016).

Tak kalah pentingnya dengan kepala sekolah, guru juga merupakan komponen yang memegang peranan dalam bidang pendidikan. Keberhasilan pendidikan lebih banyak ditentukan oleh kemampuan guru dalam melaksanakan tugasnya (Ardi, 2017; Ardi \& Erlamsyah, 2017; Daharnis \& Ardi, 2016, 2017). Sebagai komponen penting dalam pendidikan di sekolah terdapat 5 tugas pokok yang harus dikerjakan oleh setiap guru, antara lain: (1) menjabarkan isi kurikulum, yaitu tugas guru dalam menyusun perencanaan pembelajaran, seperti menyusun program tahunan, semesteran, mingguan sampai ke program harian; (2) melaksanakan pembelajaran, yakni tugas guru menyampaikan tujuan dan materi pembelajaran, dengan memilih metode, penggunaan alat/media dalam pembelajaran; (3) melaksanakan evaluasi/penilaian; (4) melaksanakan tugas dengan rasa tanggung jawab; (5) melaksanakan disiplin dalam arti luas (Ramadoni et al., 2016). Kinerja guru mempunyai spesifikasi tertentu. Kinerja guru dapat dilihat dan diukur berdasarkan spesifikasi atau kriteria kompetensi yang harus dimiliki oleh setiap guru. Wujud perilaku kinerja guru yang dimaksud adalah kegiatan guru dalam proses pembelajaran.(Yunus, 2015).

Tugas guru seperti yang dikemukakan di atas, adalah salah satu tugas diantara tugastugas guru yang lainnya. Belum pantas seseorang itu dikatakan berprofesi guru, bila tugas pokok di atas belum dilaksanakannya dengan baik, sebab hal ini merupakan tugas minimal yang harus dilaksanakan seorang guru (Ardi, Putra, \& Ifdil, 2017; Ardi, Viola, \& Sukmawati, 2018; Ardi \& Sukmawati, 2017; Daharnis \& Ardi, 2018). Namun kenyataan yang terjadi di lapangan, terutama di SMKN 1 Kerinci, Propinsi Jambi, masih ada guru yang mengabaikan pelaksanaan 
tugas pokoknya tersebut. Diantaranya dapat diamati dari: 1) Adanya guru yang belum menyusun Rencana Pelaksanaan Pembelajaran (RPP) dan batas pelajaran dengan baik; 2) Banyaknya guru dalam proses belajar mengajar belum menggunakan alat/media pembelajaran; 3) Adanya guru yang belum memiliki alat evaluasi/penilaian seperti kumpulan LKS dan bank soal rakitan sendiri. Latihan yang dikerjakan siswa kurang terkoreksi dengan baik. Buku nilai belum diisi sesuai ketentuan. Belum terlihat adanya program tindak lanjut dari pelaksanaan evaluasi/penilaian.

Sebagai kepala sekolah penulis menyadari bahwa permasalahan-permasalahan seperti di atas tidak boleh dibiarkan berlarut-larut. Penulis mencoba merenung dan merencanakan tindakan pembinaan yang sering disebut sebagai kegiatan supervisi pendidikan. Penulis akan mencoba meneliti pelaksanaan tindakan yang direncanakan tersebut untuk mengungkapkan sejauh mana peranan supervisi kepala sekolah dapat membantu pelaksanaan tugas pokok guru SMKN 1 Kerinci, Propinsi Jambi dalam merencanakan, melaksanakan dan mengevaluasi pembelajaran.

\section{METODE PENELITIAN}

Jenis penelitian ini adalah penelitian tindakan sekolah (PTS). Penelitian ini menggunakan pendekatan kualitatif (Lubis, 2018; Zulfiani, Herlanti, \& Sofyan, 2016). Pendekatan ini dipilih dengan alasan penulis akan mengungkapkan peranan supervisi kepala sekolah terhadap pelaksanaan tugas pokok guru dalam merencanakan, melaksanakan dan mengevaluasi pembelajaran. Penelitian tindakan yang meliputi: (a) perencanaan tindakan berdasarkan kepada permasalahan yang dihadapi; (b) pelaksanaan tindakan; (c) pengamatan dan pengumpulan data; (d) analisis data hasil penelitian; (e) refleksi (perenungan) hasil analisis; (f) perubahan/revisi perencanaan untuk pengembangan selanjutnya.Sesuai dengan jenis penelitian tindakan, kegiatan penelitian ini direncanakan menggunakan prosedur kerja yang dipandang sebagai suatu siklus spiral, yang terdiri dari 2 (dua) siklus. Berdasarkan refleksi (perenungan) terhadap hasil pengamatan awal atau studi pendahuluan, tindakan dilakukan pada siklus I dan II. Pada setiap siklus dilakukan perencanaan tindakan, pelaksanaan/observasi, analisis data dan refleksi.

Penelitian Tindakan Sekolah (PTS) ini dilaksanakan pada semester pertama tahun pelajaran 2018/2019. Hal ini diputuskan setelah mengamati pelaksanaan tugas pokok guru dalam menyusun perencanaan, melaksanaan proses pembelajaran dan dalam mengevaluasi proses pembelajaran dinilai belum maksimal. Pelaksanaan tugas guru dalam merencanakan pembelajaran akan dilihat dari Rencana Pelaksanaan Pembelajaran (RPP) dan batas pembelajaran yang disusun guru. Pelaksanaan tugas guru dalam proses pembelajaran akan dilihat dari kegiatan membuka dan menutup pembelajaran, penyampaian materi, penggunaan metode, alat/media pembelajaran. Data tentang pelaksanaan evaluasi pembelajaran akan diamati dari bank soal, analisis, buku nilai, dan program tindak lanjut yang disusun guru.

\section{HASIL DAN PEMBAHASAN}

Berdasarkan data hasil pengamatan pada saat studi pendahuluan, dapat disimpulkan bahwa pelaksanaan tugas pokok guru belum terlaksana dengan baik sesuai dengan harapan. Rata-rata nilai pelaksanaan tugas pokok guru berada pada angka 44. Hal ini masih jauh dari harapan. Setelah dilakukan refleksi, penulis mengadakan pertemuan membicarakan pelaksanaan tugas pokok guru, memberi arahan dan petunjuk serta menyepakati untuk diadakan tindakan supervisi menggunakan teknik kunjungan kelas.

Tabel 1. Pelaksanaan Tugas Pokok Guru pada Tindakan Siklus I

\begin{tabular}{|c|c|c|c|c|c|c|c|}
\hline \multirow[t]{2}{*}{ No. } & \multirow[t]{2}{*}{ AspekObservasi } & \multicolumn{6}{|c|}{ GuruMataPelajaran } \\
\hline & & $\underset{\mathbf{a}}{\text { Agam }}$ & Mtk & $\begin{array}{c}\overline{\mathbf{P K}} \\
\mathbf{N}\end{array}$ & B.Indo & B.Ing & Pjs \\
\hline $\begin{array}{c}\text { A. } \\
1 .\end{array}$ & $\begin{array}{l}\text { Perencanaan } \\
\text { Pembelajaran }\end{array}$ & 65 & 70 & 65 & 65 & 65 & 65 \\
\hline
\end{tabular}




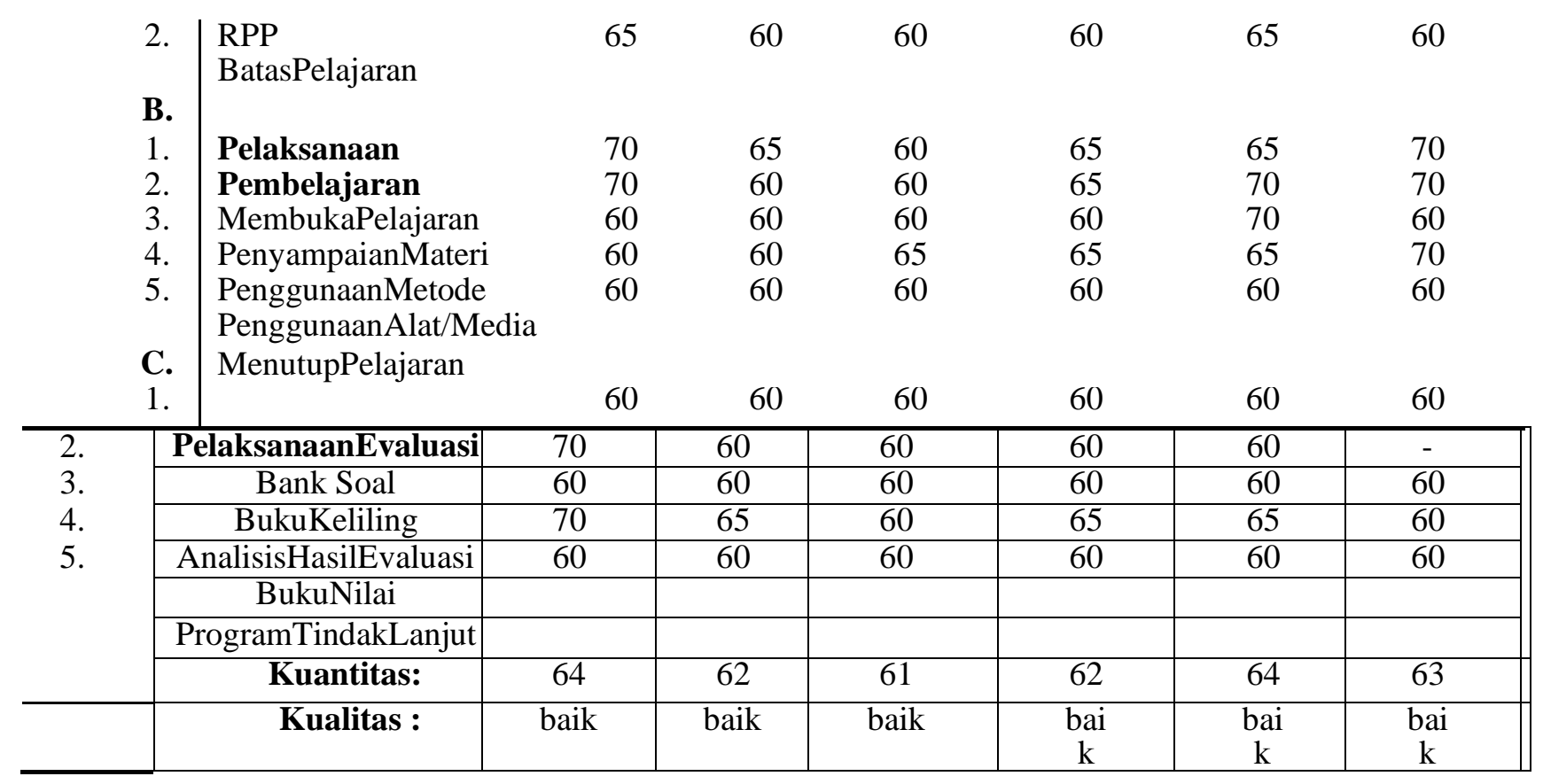

Berdasarkan data hasil pengamatan terlihat bahwa telah ada peningkatan terhadap pelaksanaan tugas pokok guru. Penulis masih ingin melajutkan tindakan. Setelah dilakukan refleksi/perenungan, penulis mengadakan pertemuan individual dengan masing-masing guru, penulis memberi arahan dan petunjuk serta menyepakati untuk diadakan tindakan supervisi berikutnya. Supervisi ini akan didahului dengan kegiatan demonstrasi mengajar oleh kepala sekolah. Setelah demonstrasi mengajar, diadakan diskusi tentang demonstrasi mengajar yang dipertunjukkan kepala sekolah. Koreksi dan penguatan yang disepakati pada diskusi tersebut menjadi catatan pada pelaksanaan supervisi berikutnya.

Tabel 2. Pelaksanaan Tugas Pokok Guru pada Tindakan Siklus II

\begin{tabular}{|c|c|c|c|c|c|c|c|}
\hline \multirow[t]{2}{*}{ No. } & \multirow[t]{2}{*}{ AspekObservasi } & \multicolumn{6}{|c|}{ GuruMataPelajaran } \\
\hline & & $\underset{\mathbf{a}}{\text { Agam }}$ & $\underset{k}{\operatorname{Mtmt}}$ & PKN & $\begin{array}{c}\text { B.Indonesi } \\
\text { a }\end{array}$ & B.Ing & $\underset{S}{\text { Penja }}$ \\
\hline A. & Perencanaan & & & & & & \\
\hline 1. & Pembelajaran & 70 & 75 & 65 & 70 & 75 & 70 \\
\hline 2. & $\begin{array}{l}\text { RPP } \\
\text { BatasPelajaran }\end{array}$ & 75 & 65 & 60 & 65 & 70 & 60 \\
\hline B. & & & & & & & \\
\hline 1. & Pelaksanaan & 75 & 70 & 70 & 70 & 70 & 70 \\
\hline 2. & Pembelajaran & 75 & 70 & 70 & 70 & 70 & 70 \\
\hline 3. & MembukaPelajaran & 75 & 65 & 65 & 65 & 70 & 65 \\
\hline 4. & PenyampaianMateri & 70 & 65 & 65 & 70 & 70 & 70 \\
\hline 5. & $\begin{array}{l}\text { PenggunaanMetode } \\
\text { PenggunaanAlat/Media }\end{array}$ & 70 & 65 & 65 & 65 & 65 & 65 \\
\hline C. & MenutupPelajaran & & & & & & \\
\hline 1. & & 75 & 65 & 65 & 70 & 65 & 60 \\
\hline 2. & PelaksanaanEvaluasi & 75 & 65 & 65 & 65 & 65 & - \\
\hline 3. & Bank Soal & 75 & 65 & 65 & 65 & 65 & 60 \\
\hline 4. & BukuKeliling & 75 & 70 & 65 & 70 & 70 & 70 \\
\hline 5. & $\begin{array}{l}\text { AnalisisHasilEvaluasi } \\
\text { BukuNilai }\end{array}$ & 70 & 70 & 65 & 65 & 70 & 65 \\
\hline & $\begin{array}{l}\text { ProgramTindakLanjut } \\
\text { Kuantitas: }\end{array}$ & 73 & 68 & 65 & 68 & 69 & 66 \\
\hline & Kualitas : & baik & baik & baik & baik & baik & baik \\
\hline
\end{tabular}


Berdasarkan data hasil pengamatan pada tabel 2 di atas, terlihat bahwa semua guru telah melaksanakan tugas pokoknya dengan baik. Semua guru telah memiliki RPP dan batas pelajaran. Pada jam-jam longgar, guru-guru terlihat aktif melengkapi program pembelajaran rakitan sendiri, terlihat aktif dan kreatif mengupayakan alat/media yang akan digunakan dalam proses pembelajaran. Semua guru telah memperlihatkan usahanya melaksanakan evaluasi sesuai dengan ketentuan-ketentuan yang telah ditetapkan.

\section{Pembahasan}

Pada bagian ini dikemukakan pembahasan berdasarkan temuan-temuan penelitian yang berkaitan dengan pokok pikiran-pokok pikiran yang dituangkan dalam latar belakang masalah serta dikaitkan dengan teori-teori yang relevan. Berdasarkan hasil pengamatan pada saat studi pendahuluan, menunjukkan bahwa pelaksanaan tugas pokok guru SMK Negeri 1 Kerinci, belum terlaksana dengan baik. Berdasarkan hasil pengamatan pada penelitian tindakan siklus pertama, diperoleh data bahwa telah ada peningkatan terhadap pelaksanaan tugas pokok guru. Namun masih tergolong jauh dari harapan yang sesungguhnya. Supaya pelaksanaan tugas pokok guru dapat terlaksana dengan baik, maka kepala sekolah mengadakan pertemuan individual dengan masing-masing guru yang diamati untuk membicarakan pelaksanaan tugas pokok guru yang bersangkutan, memberi arahan dan petunjuk serta menyepakati untuk diadakan tindakan supervisi berikutnya.

Agar lebih maksimalnya hasil pembinaan/supervisi kepala sekolah ini, maka diadakan kegiatan demonstrasi mengajar oleh kepala sekolah. Untuk membantu pelaksanaan tugas guru, kepala sekolah perlu menunjukkan bagaimana cara mengajar yang baik. Setelah demonstrasi mengajar, diadakan diskusi tentang demonstrasi mengajar yang pertunjukkan kepala sekolah. Koreksi dan penguatan yang disepakati pada diskusi tersebut menjadi catatan pada pelaksanaan supervisi berikutnya. Berdasarkan hasil pengamatan pada penelitian tindakan siklus kedua, ternyata supervisi yang dilaksanakan kepala sekolah dapat meningkatkan pelaksanaan tugas pokok guru. Hal ini membuktikan bahwa supervisi kepala sekolah punya peranan yang sangat penting dalam meningkatkan pelaksanaan tugas pokok guru.

\section{KESIMPULAN}

Sebelum diadakan tindakan supervisi oleh kepala sekolah terhadap pelaksanaan tugas pokok guru SMK Negeri 1 Kerinci, terindikasi bahwa adanya guru yang belum menyusun perencanaan pembelajaran, belum menggunakan alat/media dalam pembelajaran, belum menyusun program evaluasi, ulangan hasil belajar kurang terkoreksi, buku nilai dan program tindak lanjut belum dikerjakan dengan baik. Hasil penelitian membuktikan bahwa setelah dilaksanakan supervisi kepala sekolah, pelaksanaan tugas pokok guru jauh lebih meningkat. Semua guru telah mempunyai RPP dan batas pelajaran. Proses pembelajaran berjalan dengan baik, menggunakan metode, alat/media yang sesuai dengan materi pembelajaran. Evaluasi telah terkelola dengan baik.

\section{DAFTAR PUSTAKA}

Ardi, Z. (2017). Unsuitable Majoring: Does the Reorientation Would Help the Student for Revitalize Learning Activities? In Proceedings of the 9th International Conference for Science Educators and Teachers (ICSET 2017). Paris, France: Atlantis Press. https://doi.org/10.2991/icset-17.2017.69

Ariana, I. W., Dantes, N., \& Lasmawan, I. W. (2015). Kontribusi Supervisi Kepala Sekolah, Motivasi Berprestasi dan Komitmen Kerja Terhadap Kinerja Guru di Gugus Sekolah VIII Kecamatan Abang. PENDASI: Jurnal Pendidikan Dasar Indonesia, 5(1).

Bogler, R., \& Nir, A. E. (2015). The contribution of perceived fit between job demands and abilities to teachers' commitment and job satisfaction. Educational Management Administration \& Leadership, 43(4), 541-560.

Ekosiswoyo, R. (2016). Kepemimpinan kepala sekolah yang efektif kunci pencapaian kualitas pendidikan. Jurnal Ilmu Pendidikan, 14(2). 
Fitrah, M. (2017). Peran kepala sekolah dalam meningkatkan mutu pendidikan. Jurnal Penjaminan Mutu, 3(1), 31-42.

Mette, I. M., Range, B. G., Anderson, J., Hvidston, D. J., \& Nieuwenhuizen, L. (2015). Teachers' Perceptions of Teacher Supervision and Evaluation: A Reflection of School Improvement Practices in the Age of Reform. Education Leadership Review, 16(1), 1630.

Nirwana, A., \& Murniati, A. R. (2015). Strategi Kepala Sekolah Dalam Meningkatkan Kompetensi Profesional Guru Pada SD Negeri 2 Kota Banda Aceh. Jurnal Administrasi Pendidikan: Program Pascasarjana Unsyiah, 3(4).

Park, J. H., \& Ham, S. H. (2016). Whose perception of principal instructional leadership? Principal-teacher perceptual (dis) agreement and its influence on teacher collaboration. Asia Pacific Journal of Education, 36(3), 450-469.

Purwanti, K., Murniati, A.R. dan Yusrizal. 2014.Kepemimpinan Kepala Sekolah DalamMeningkatkan Kompetensi Guru PadaSMP Negeri 2 Simeulue Timur. JurnalIlmiah DidaktikaXIV(2), 390-400.

Ramadoni, W., Kusmintardjo, K., \& Arifin, I. (2016). Kepemimpinan Kepala Sekolah dalam Upaya Peningkatan Kinerja Guru (Studi Multi Kasus di Paud Islam Sabilillah dan Sdn Tanjungsari 1 Kabupaten Sidoarjo). Jurnal Pendidikan: Teori, Penelitian, Dan Pengembangan, 1(8), 1500-1504.

Rosyada, Dede. (2013). Paradigma Pendidikan Demokratis, Sebuah Model Pelibatan Masyarakat dalam Pendidikan. Jakarta: Prenada Media.

YUNUS, M. (2015). Kinerja Guru dalam Menyelenggakan Penilaian Kognitif pada Pembelajaran Matematika di SMP Negeri se-Kecamatan Keera Kabupaten Wajo (Doctoral dissertation, Pascasarjana). 